\title{
Middle Passage: In the Absence of Detail, Presenting and Representing a Historical Void
}

\author{
RINALDO WALCOTT \\ Women and Gender Studies Institute, University of Toronto
}

\section{Introduction: Middle Passages}

What might it mean to imagine the Middle Passage? What work does imagining the Middle Passage do? Despite its centrality in invocations of transatlantic slavery, representations of the Middle Passage are few. By representations of the Middle Passage, I mean artistic representations across literature, film, music, and visual art that seek to offer imaginative insights into its horrors. M. NourbeSe Philip's 2008 long poem, Zong! not only documents the murder of some 150 Africans aboard the slave ship from which the poem takes its name, it does something more. The poetics of Zong! enacts those that have gone missing, and thus emerges into a void to place into evidence that which we assumed we had lost. The work of imagination in the poem replaces that which we might think had gone missing prior to its poetic representation. Through reworking and reordering the legal decision in the 1783 court case, Gregson v. Gilbert, ${ }^{1}$ Philip's poem recounts the story of the slave ship Zong. The poem re-presents the evidence of the mass murder in the voice of those we might otherwise not hear in such legal documents, in this instance that of Setaey Adamu Boateng.

Philip shares authorship of Zong! with Setaey Adamu Boateng, who she tells us guided her and aided her in the recovery and creation the story of the Zong. In this case then, Zong! also exceeds the poem as a form and genre, and even as an event in the proper use of that term. To do so, Philip must break language and break with language. The very page, the architecture of each page of the poem spatialises the break with language, and its representation on the page, as one of voids and or missingness, and simultaneously fills those gaps with knowledge, with untold history, with people and lives that would otherwise remain unknown. Philip's Zong! is a poem that is a sort of return, but a return, too, brings with it the problem of the missing, the problem of the void. It is a poem that requires us to think the Atlantic Ocean differently and anew.

The pages of Zong! exhibit a labour that is intellectual, psychical and psychic, and demands a certain commitment from the reader. Philip, as poet, does not tell the story. Instead, the poet is the medium for Setaey Adamu Boateng; the poet repeats the story as told to her in the form of the written text. Immediately, Philip draws on a practice that is doubled: the 'as told to' is a central element of the slave narrative in

1 Gregson v. Gilbert, 3 Dougl. 233 at 629 (1783), available at http://www.commonlii.org/int/cases/EngR/1783/85.pdf (accessed December 2018). 
the Americas - often the enslaved's stories was told to white people and then reproduced with much missing from them. But in this particular doubling, it is 'as told to' a descendent of transatlantic slavery, whose language cannot fully inhabit the dreadful details, even though she must and does do so. This doubling does something to how we might think the Atlantic Ocean as a (crime) scene, as a space and geography of modernity, but simultaneously also as a doubled venture of brutal origins, potentialities and possibilities.

The Atlantic Ocean, being one of the world's most turbulent bodies of water, made entering and crossing into the zone of the Americas particularly difficult. The overcrowded and often not very seaworthy old ships, bearing their African human cargoes, added nothing to the smoothness of the journey. The specific leg of the journey and crossing known as the Middle Passage ${ }^{2}$ carries much significance for the Black diaspora, because it was in the acts of the crossing that the ruptures of transatlantic slavery began to take root, making Black people the symbols and symptoms of an emergent modernity. When considering the Middle Passage, the passage from life to death to life again is most poignant. ${ }^{3}$ I am persuaded by Barbara Christian's insights that the Middle Passage represented a significant life crisis for those Africans who survived the crossing. ${ }^{4}$ In some ways, or at least in conjunction with plantation and other configurations of slavery, the crossing was a horrific psychic crisis for all involved. And although it was different for each slave, I see this crisis as a collective trauma for Black people specifically. The crossing of the Atlantic and the many deaths that occurred, denied Africans the opportunity to put their dead to rest in ways that accorded with their customs. As Christian points out, Africans could not mourn their dead in ways that might allow them to get over the loss and attach to new objects of pleasure.

These catastrophic traumatic events are central to how the Middle Passage is remembered, disremembered, forgotten and recuperated in the Americas, and to how it goes missing. The inability to lay one's dead to rest by way of making the necessary arrangements is one of the most painful wounds of the Middle Passage. In the reality of what has become a historical inability of laying one's dead to rest, the wound remains open. How that wound is responded to is of particular importance to my concerns in this essay in its consideration of missingness. Three tensions organise and inform this essay.

Firstly, to make sense of the West, or at least the Americas, is to grapple with its violent origins. That these violent origins are repressed (or go missing) in the narratives of modernity reflects a refusal to engage with the multiple violent ruptures and

2 The Middle Passage is sometimes, though not often, referred to as the 'Bitter Passage'. The Bitter Passage gave birth to Black diasporic communities in the Americas; see for example, A. D. Austin, African Muslims in Antebellum America (New York: Routledge, 1997). As the second leg of the Triangular Trade, the Middle Passage was the crossing of the Atlantic Ocean from Africa to the Americas (the first leg being from Europe to the west coast of Africa, and the third being from the Americas back to Europe). See E. Brathwaite, The Development of Creole Society in Jamaica, 1770-1820 (London: Oxford University Press, 1971); P. Gilroy, The Black Atlantic (Cambridge, MA: Harvard University Press, 1993); W. Rodney, How Europe Underdeveloped Africa (Washington DC: Howard University Press, 1982); and E. Williams Capitalism and Slavery (London: Andre Deutsch, 1964).

3 Robert Hayden's poem 'Middle Passage' is a good example of this. R. Hayden, Collected Poems: Robert Hayden, Frederick Glaysher (ed.) (New York: Liveright, 1985).

4 B. Christian, 'Fixing Methodologies: Beloved', Cultural Critique, Spring 1993, 5-15. 
departures that inaugurated the hemisphere as we have come to know it and live it. The wilful disregard for the African human that the late-Enlightenment conquest and colonisation of the Americas represents must, and does, return in numerous ways as a form of missingness.

Secondly, the Black diaspora, that came into being in the violent origins of the West, the Americas and thus modernity, offers its most violent rupture - the Middle Passage - as a possibility for working through the trauma of modernity. In this essay, I want to acknowledge the loss, a kind of missingness that the Middle Passage represents. I want to acknowledge this, not as a loss of identity but as a loss to the politics and culture of memory. In effect, it is the loss of a certain kind of archive - yet another missingness.

Thirdly, to acknowledge this loss to the archive of political and cultural memory, I turn to representative strategies. I see representation as a kind of reparation making, ${ }^{5}$ a working through of the acknowledgement of the missing or lost. In particular, the violent origins of the loss gave birth to my central concern in this essay: the violent origins of modernity as trauma gave birth to the Black diaspora as symbol and symptom of the loss. But it gave birth to a diaspora that is, and in many ways can only be, constituted from fragments and a lack of details, constituting an impossible forensics. The Black diaspora does not come bearing narrative accounts and first-hand tales of the crossing. Instead, where such accounts exist, very little detail is offered upon which one might actively speculate about the horrific nature of entering and crossing the Middle Passage. ${ }^{6}$ The void is a time lag. Thus the inability to grasp the magnitude of the Middle Passage is always an event too soon and too late.

I want to make the case that, for Black diaspora people, modernity is a site of trauma, and that its violent origins return to structure our present. I argue that the continuation of the project of modernity represents, for Black people, the continuation of a trauma of which we are both a collective symbol and a symptom of its outcome. Following Sylvia Wynter, my project acknowledges that what we need to bring 'to an end is the entire history of these past five hundred years'. Wynter makes the case for ushering in a new kind of 'humanism', arguing that 'what should constitute fully modern human beings is now the necessary condition, at this conjuncture, both of our species' survival and, concomitantly, of our interaltruistic co-identification as a species. ${ }^{7}$

Wynter's language is laced with, and influenced by, languages of science, not because she is persuaded that science has an answer, but because her selective use of its language allows for a particular move away from foundational identity claims to making claims on behalf of human forms of life, or claims 'from the perspective of as a significant part of his crossing and arrival in the Americas but he does not linger there. Such ambivalence is an indication of the unspeakable nature of the event. O. Equiano, 'The Interesting Narrative of the Life of Olaudah Equiano or Gustava Vassa, the African' 1814, in H. L. Gates (ed.), The Classic Slave Narratives (New York: Mentor, 1987).

7 S. Wynter, '1492: A New World View', in V. Lawrence Hyatt and R. Nettleford (eds), Race, Discourse, and the Origins of the Americas: A New World View. (Washington DC: Smithsonian Institution, 1995), 6-8. 
the species.8 This is an important shift because it implicates us all in the possibility of any resolution. Modernity and its representative strategies have long placed some of us, and Black people specifically, outside of its confines. Yet modernity also continually returns evidence to the contrary.

In David Dabydeen's long poem, 'Turner', which was written as a riposte to J. M. W. Turner's 1840 painting, Slavers Throwing Overboard the Dead and Dying: Typhoon Coming On (commonly referred to as The Slave Ship), he suggests that the Middle Passage should be taken as a 'memory of ancient cruelty. ${ }^{9}$ His response to Turner was to write a poem that speaks in the imagined voice of those now silent. Dabydeen's words are an attempt to fill the spaces emptied by Turner's painting. The poem brings to life the imagined voices of those who perished in the crossing but, even more importantly, it brings those voices into contact with those who survived, as a way to make reparation. This epic poem offers more than postcolonial readings currently allow for. ${ }^{10}$ When reading Dabydeen's Turner along with Zong!, an entire assault on modernity unfolds.

Dabydeen's poem is a working through of the collective traumas of the Middle Passage, the crossing of the Dark Waters (the term Indian indentured workers used for their crossing to the Americas) and the tremors of modernity for the subaltern. Dabydeen infuses those emptied spaces with responses that not only trouble the celebration of the painting, but also have broader implications for troubling paradigms of modernity. Dabydeen's poem writes the history of modernity as a traumatic, creolising story, infused with subaltern resistance and struggles over its meanings. The fractures of, and in, modernity are what constitute it as a trauma.

Dabydeen's poem can also be a signpost pointing to a potential conversation between Turner's Slave Ship and Tom Feelings' book of pencil drawings, The Middle Passage. ${ }^{11}$ Feelings' drawings are intent on replaying and displaying the horrors of slavery from the African continent to the Americas. While the drawings seem to work toward a specific narrative of history as salvation and commemoration, at times the art cannot sustain this view and breaks down, perhaps for the better; revealing the missingness of it can be insightful. While Turner is interested in representing the sublime, with its menacing beauty and potential dangers, Feelings' project, like Dabydeen's, is to occupy a historical void while simultaneously gesturing to the absent presence of detail. The poem and the drawings fill the time lag.

\section{Tom Feelings' The Middle Passage: reading images of trauma}

I now turn more fully to Feelings' artwork. In The Middle Passage, Feelings offers an account that seeks to imagine and represent the horrors of the journey as fully as possible. His pencil drawings fill an imaginative void, returning to us that which

Wynter, 'A New World View', 8.

D. Dabydeen, Turner: New and Selected Poems (London: Cape Poetry, 1994).

0 Nonetheless, for an interesting reading of the poem as a postcolonial text, see T. Doring, 'Turning the Colonial Gaze: Revisions of Terror in Dabydeen's “Turner”, Third Text, 38, Spring, 1997.

T. Feelings, The Middle Passage (New York: Dial, 1995). 
was missing from the archive. Feelings' graphics work to put the unimaginable into play and to fill a gap in the archive. The drawings do not merely return that which is missing, but require us, as analysts, to confront what missingness might do. By this I mean the drawings require us to confront how missingness might, and can, shape our relationship to history, memory and trauma. Feelings' illustrations offer us a way into an extended discussion of how missingness shapes the ways in which a Black diasporic psychic life comes into being. His drawings are an attempt to bring some detail to the Middle Passage, as a way to accomplish a public and collective working through of this cultural trauma.

Let me cite an observation made by Cathy Caruth as a way to ground my concerns with Feelings' exemplary illustrations. Writing about post-traumatic stress disorder (PTSD), Caruth states that

possession of the past ... has become a central characteristic of the survivor experience of our time. Yet, what is particularly striking in this singular experience is that its insistent reenactments of the past do not simply serve as testimony to an event, but may also, paradoxically enough, bear witness to a past that was never fully experienced as it occurred. ${ }^{12}$

Caruth's ideas, I believe, are quite applicable to the cultural traumas of diasporic Black people. Caruth is concerned with the role of the flashback for individuals with PTSD. Yet, I want to suggest that, in the absence of detail, imaginative works act as the flashback. Feelings' artwork is therefore not merely an attempt to narrate an antihistory of transatlantic slavery, but operates metaphorically on the psychical level. But even more than that, the work attempts to, as Caruth put it 'bear witness to a past that was never fully experienced as it occurred.

Feelings' illustrations stand in as a collective and cultural flashback that makes the incomprehensibility of having survived the Middle Passage liveable. Giving his book the subtitle, White Ships, Black Cargo, Feelings attempts to bring the discourse of race and the practices of racialisation to the fore. Immediately readers are confronted with one of the major outcomes of what Sylvia Wynter calls the post-1492 voyages: the establishment and creation of rules of ordering, through which the physical and epistemic violence of the Enlightenment, and later the rise of modernity, was made possible. That 'Black cargo' is the term used for the occupants in the holds of the ship means that Feelings' work is also about a particular kind of rescue mission or a working through of what has been repressed. The drawings represent a different telling of the history of the Middle Passage, and of what it means to read the Middle Passage as a founding moment of modern trans-shipped cultures.

Few discussions of the Middle Passage use the language of conquest but Feelings' graphic artworks open with the violent conquest of Africans. Images of Europeans with guns murdering Africans are among the first illustrations in the book. Yet 
Feelings does not stop there; rather he makes the pictorial narrative more complex by displaying African collusion with the violent rupture and departure. ${ }^{13}$ The fundamental difference between Feelings' drawings and Turner's painting is that Feelings is trying to represent a cultural trauma. I want to make the case that when confronted with the horrors of the Middle Passage we are confronted with a different kind of trauma. By this I mean that, in the aftermath or the time lag between the initial experience of violent rupture and departure, and its repetition in various symptoms (chief among which is racism), we confront a cultural trauma. I use the term cultural trauma to both embrace Jacques Le Goff's notion of 'collective trauma', ${ }^{14}$ and to signify that the trauma of the Middle Passage is the basis of something greater - a trauma that is lived out every day as symptoms of the violent origins of modern society.

Le Goff argues that collective trauma comes out of violent and catastrophic events. He offers the example of the destruction and decimation of the Inca Empire by the European colonising forces. While he advances the idea of collective trauma in relation to the writing of history (an issue which bears heavily on this work but which I cannot take up here), Le Goff is clear that collective traumas require, and bring with them, a response. I suggest that this response is located between two kinds of trauma: that of the collective and its reworking or return in the cultural. Le Goff finds this response in what he argues is referred to by the vanquished as 'tradition'. Tradition becomes a counter to the coloniser's narrative of history. What Le Goff calls 'tradition', 'slow history' or 'anti-history' is what he sees as a cultural response to the magnitude of collective trauma. In the examples I have discussed here, poems and artworks return to an enactment of the trauma as something to both examine and come to terms with. These cultural texts constitute an anti-history of hegemonic modernity. But because this anti-history becomes a part of the collective memory and unconscious of the vanquished, it also shifts into a cultural trauma. It is, if you will, the attempt to hold onto and recover some of the detail of a past that is no longer present in an effort to make the present a site for the possibility of life and living.

I rehearse Le Goff's notion of collective trauma because I think it bears heavily on the idea of cultural trauma. In fact, cultural trauma might be said to begin both literally and metaphorically with what Caruth calls a retrospective departure. She notes that a trauma is an 'unwitting reenactment of an event that one cannot simply leave behind. ${ }^{15}$ Similarly, Sigmund Freud observes of one patient: 'He is obliged to repeat the repressed material as a contemporary experience instead of, as the physician would prefer to see, remembering it as something belonging to the past. ${ }^{16}$ It is exactly in the tension between something belonging to the past and repeating it as a contemporary experience where cultural trauma lies.

In a situation such as the Middle Passage, where the absence of detail returns, the existence and recognition of the historical void is the second or retrospective blow

The artworks begin with an attempt to demonstrate and represent a realist narrative of the collusion between European conquerors and African royal elites.

14 J. Le Goff, History and Memory, S. Rendall and E. Claman (trans) (New York: Columbia University Press, 1992 ), 146.

15 C. Caruth, Unclaimed Experience: Trauma, Narrative, and History (Baltimore, MD: Johns Hopkins University Press, 1996$), 2$.

S. Freud, Beyond the Pleasure Principle, James Strachey (trans.) (New York: W.W. Norton, 1961), 19, emphasis in original. 
that makes the time of trauma continuous and discontinuous. The traumatic experience of the Middle Passage is, as Carl Pedersen observes, 'not confined to the hold of the slave ship; it invades the consciousness of all who enter the Atlantic zone. ${ }^{17}$ What Pedersen offers us is a Fanonian sociogenic reading. Fanon offered sociogeny as a way of moving us away from individual ontogeny, thus encouraging us to think about trauma in relation to larger social, political and cultural matters. This is important because I am arguing that once the Middle Passage is read as a constituent element of modernity, there is no 'outside' to it. We merely occupy different places in relation to narratives about it.

The diasporisation of Black people as transatlantic slaves did not simply leave other places and spaces unchanged. Thinking merely at that level, the implications of our collective involvement are apparent. But I am also suggesting that our cultural practices and everyday lives are imbued with the traumas of the Middle Passage, including the 'debris' and the 'flotsam and jetsam of a distant past.'. ${ }^{18}$

If we accept that the violent rupture and departure that is the Middle Passage is one of the fundamental constituent elements of the making of the Americas, with another being the genocide and colonisation of Indigenous peoples, then we arrive at the Freudian insight that it takes two traumas to make one. The two traumas (constituting one trauma) that the Americas are, and remain, marked by the enslavement of Africans and genocidal colonisation of Indigenous peoples. As a cultural space, the Americas become a space or site of the traumatic, but daily living in the Americas is a (dis)continuous aspect of the trauma. For Black people then, the incomprehensibility of survival in the Americas is also a component of the traumas of the Middle Passage. 'The unbearable nature of the event' and 'the unbearable nature of its survival, ${ }^{19}$ as Caruth puts it, are what continues to occasion repetitions of the Middle Passage as a cultural trauma for Black diaspora people. Once again, the absent presence of detail is what defines this traumatic experience.

However, what I find most interesting about the representations of the horrors depicted in the pencil drawings is the breakdown in the realist narrative as Feelings tries to represent the interior of the ship and the atrocities committed there. That is, narrative breaks down when entering the ship, and simultaneously when entering the interior life of the captured and enslaved. But this should not be surprising. As we know, trauma is always unreal; trauma can never be anticipated.

It is this breakdown, and the inability to represent the horrors as realism, that holds the most promise for thinking about the Middle Passage as a cultural trauma. This is not a question of recovery. It is a radical rethinking of the very structures of nation, people, and various cultural and social realities and positions. It is a work of mourning. It is the crisis of witnessing the Middle Passage. What then is an adequate response and act of mourning? In Archive Fever Derrida writes,

\footnotetext{
17 C. Pedersen, 'Sea Change: The Middle Passage and the Transatlantic Imagination' in W. Sollors and M. Diedrich (eds), The Black Colombiad: Defining Moments in African American Literature and Culture (Cambridge, MA: Harvard University Press, 1994), 49.

18 Le Goff, History and Memory, 147.

19 Caruth, Unclaimed Experience, 8.
} 
In an enigmatic sense, which will clarify itself perhaps (perhaps, because nothing should be sure here, for essential reasons), the question of the archive is not, we repeat, a question of the past. It is not the question of a concept dealing with the past that might already be at our disposal or not at our disposal, an archivable concept of the archive. It is a question of the future, the question of the future itself, the question of the response, of the promise and of a responsibility for tomorrow. ${ }^{20}$

While Derrida is certainly concerned with a different archive from the one I am currently investigating, much of what he has to say concerning conceptualisations of the archive has important bearing on my reading of Feelings' drawings. I believe Feelings to be much more concerned with a response to a possible future or tomorrow than with a realist return to the past. I think this is why the realist narrative breaks down, and precisely why the graphics cannot, and do not, sustain a realist narrative. The illustrations are meant to allow for a particular working through of a cultural trauma that can never be brought to closure nor grasped as it first occurred. Artworks of the Middle Passage are, in effect, representations that memorialise not death but living. This is what Feelings has to say concerning his emotional commitment to the drawings:

But if this part of our history could be told in such a way that those chains of the past, those shackles that physically bound us together against our wills could, in the telling, become spiritual links that willingly bind us together now and in the future - then that painful Middle Passage could become, ironically, a positive connecting line to all of us whether living inside or outside the continent of Africa.

Feelings is constantly aware of the tensions between what he calls this 'African story' and something else. He admits the only place that he could complete the drawings was in New York City. This acknowledgement is, in fact, a crucial element of the basis for why history is always about the present.

As the book progresses, Feelings' drawings move from a kind of attempt at 'historical realism' to a much more fragmented and collaged representation of captured Africans and the slave ships. I am particularly taken by a drawing that recurs twice in the book. ${ }^{21}$ The image is of two African heads that appear at first to protrude from the ship's bow and seem to act as guides for the ship's journey. However, at second glance, the heads appear to be beside the ship, not protruding from the ship's bow. In the smaller version of the image, the heads seem to have screaming mouths, one more than the other. In the larger version, deep in the book, and spanning two pages, African bodies packed into the hold of the ship are clearly visible. introduction (John Henrik Clarke), the publisher's imprint, and the place of publication (New York). 
The image is interesting to me, and clearly also to stakeholders in the project who singled it out as an inset piece. The image evokes the connection between Black bodies and the technologies of transatlantic slavery in a way that the conquering violence of guns, swords, chains and whips cannot. The 'surrealist' posture of the image allows for a reading that opens up questions rather than attempting to put them into the orderly and fabricated seamlessness that the scientificity of history suggests. Instead, the breakdown in realism that the image represents is, in effect, a kind of flashback that immediately acknowledges that to encounter these images is not to encounter the first trauma but rather to encounter the trauma for the first time. To encounter the trauma for the first time does not leave history behind but rather drags history along, as a way to make this pictorial flashback a constitutive element of the working through of the trauma of the Middle Passage, which is also the trauma of modernity.

\section{The last crossing}

What I am suggesting is that we might be forced to look at modernity differently when the Middle Passage and its resulting traumas and their repetitions are accounted for. To see slavery and its aftermath as behind us, or to see ourselves as being beyond that time and place, is to repeat the trauma, albeit differently from its first instance. The temporal limitations of the historical narrative of the Middle Passage are reversed. The images shift and change responses to time, so that time is no longer a scarcity, the Middle Passage is no longer transient, and the possibilities for mourning can be approached. ${ }^{22}$ This work requires a new mode of identification, one that positions all of us within the trauma of modernity.

I have suggested that an inability to look honestly at modernity is the second blow of the cultural trauma. Now I suggest that a new kind of looking is required to bring us closer to acknowledging that modernity is the wound that many of us bear. As Caruth put it: 'The traumatized, we might say, carry an impossible history within them, or they become themselves the symptom of a history that they cannot entirely possess. ${ }^{23}$ What is at stake in looking at modernity differently is care of the self, the dignity of the human.

We can bring Caruth's insight to helping us rethink Black people's survival in the Americas, reading the history of Black people as a symptom of a larger history that those bodies can never fully come to know, but must nonetheless partially possess. One more shift is required, which is to begin to think how other people fit differently, and also partially, into the narrative of the terror and horrors of the Atlantic zone. To borrow a phrase from Deborah McDowell, we can learn to recognise that the Middle Passage is a part of the 'psychic architecture' of the Americas. ${ }^{24}$ This recognition might occasion a new mode of identification. This is the importance of Wynter's recourse to

\footnotetext{
See S. Freud 'On Transience' in Art and Literature, J. Strachey (trans.), A. Dickerson (ed.) (New York: Penguin, 1985).

Caruth, Trauma and Experience, 5.

D. McDowell, 'Pecs and Reps: Muscling in on Race and the Subject of Masculinities', in H. Stecopoulos and M. Uebel (eds), Race and the Subject of Masculinities (Durham, NC: Duke University Press, 1997).
} 
thinking with the language of species as an attempt to shift modernity's confines of foundational identity orderings such as race, sex, gender. In fact, the survival of Black people in the context of the Americas is the crisis and trauma of modernity writ large. Black people signify a history that we can never put behind us, and thus trouble for a story of modernity (as often told) that is devoid of our presence, as if we were not central to its making.

Feelings' artworks require that we no longer sever knowledge of the Middle Passage from the pains and enjoyments of modernity. Instead, his drawings require us to account for our inherited and proximal relations as we differently bear witness to the present (dis)continuous affects of the traumas of modernity. Indeed, Philip offers us a new psychic architecture in her Zong!. The invoking of the 'as told to the poet by Setaey Adamu Boateng' sets a different cosmology at play. This is a cosmology discredited by European modernity as both backward and savage; but it is also one that has not only survived brutality but has also been a foundational part of Black diasporic survival. It is in part my argument that these ongoing doublings, often in tension, antagonism and contradiction constitute a void or a missingness, for which all we have left to do is to figure out how we might live better together in the aftermath of the upheavals.

Ultimately, the sketch of modernity that I have been troubling here is one in which missingness structures its claims in regard to the place of Black people in its unfolding. My argument requires us to think differently about the cultural archive, and about what Black artists imagining and representing the Middle Passage might and can bring to fill the intentional void that makes Black people an absented presence in the modern. The foundation of this modernity is thus one of collective trauma, and any attempt to grapple with it fully must, of necessity, pass through Indigenous and Black accounts, as broadly construed, of the world we presently inhabit. 